\title{
Nursing Home Physicians Discuss Caring for Elderly Residents: An Exploratory Study*
}

\author{
Albert Banerjee, ${ }^{1}$ Robert James, ${ }^{2}$ Margaret McGregor, ${ }^{3,4}$ and Joel Lexchin ${ }^{2}$
}

\begin{abstract}
RÉSUMÉ
Malgré la complexité croissante des soins en foyers de soins de longue durée, le rôle des médecins dans la prestation des soins aux résidents a été peu étudié. Cette étude exploratoire internationale visait à mieux comprendre les rôles des médecins, leurs responsabilités et leurs tâches, ainsi qu'à explorer les caractéristiques uniques de la pratique médicale dans les foyers de soins de longue durée. Des entrevues ont été menées avec 18 médecins. Ces médecins ont mentionné qu'ils contribuaient fortement à la qualité des soins pour les résidents, en clarifiant les objectifs des soins, en prenant des mesures pour réduire les hospitalisations et les prescriptions de médicaments non nécessaires, et en contribuant à la formation du personnel. Les pratiques en foyers de soins de longue durée impliquaient les médecins au centre de réseaux de relations qui assuraient non seulement une meilleure qualité des soins médicaux, mais aussi une satisfaction professionnelle chez les médecins. L'importance de ces relations est telle qu'elle permettait d'aller au-delà des démarcations traditionnelles entre le domaine médical et le domaine social, et mettait en évidence qu'une bonne pratique médicale implique de bonnes pratiques sociales. Considérant la nature exploratoire de l'étude, les auteurs recommandent que de futures recherches soient menées pour mieux comprendre les dimensions relationnelles associées à la pratique de la médecine en foyers de soins de longue durée.
\end{abstract}

\begin{abstract}
Despite the increasing complexity of nursing home care, the role of physicians caring for residents is largely unexplored. This international, exploratory study sought to learn about physicians' roles, responsibilities, and tasks as well as investigate the unique qualities of medical practice in nursing homes. We conducted interviews with 18 physicians, who reported making important contributions to the quality of resident care, including clarifying the goals of care, working to reduce unnecessary medication and hospitalization, as well as contributing to staff education. Nursing home practice involved physicians in networks of relations that were instrumental to the quality of medical care and physicians' job satisfaction. The importance of these relationships disrupts the oft-drawn boundary between the medical and the social, suggesting that good medical practice depends on good social practice. Reflecting the exploratory nature of the study, we recommend research to better understand and support the relational dimensions of nursing home medicine.
\end{abstract}

1 COFAS Marie Curie Fellow, Stockhom University, Sweden

2 School of Health Policy and Management, York University, Toronto

3 University of British Columbia, Department of Family Practice, Vancouver

4 Vancouver Coastal Health Research Institute Centre for Clinical Epidemiology \& Evaluation, Vancouver

* The authors thank the physicians interviewed for participating in the study. The research for the study in this article was funded by the Social Sciences and Humanities Research Council (SSHRC) of Canada's Major Collaborative Research Initiative, "Re-Imagining Long-Term Residential Care", and the writing was supported by a COFAS Marie Curie Fellowship.

Manuscript received: / manuscrit reçu : 03/02/17

Manuscript accepted: / manuscrit accepté : 25/06/17

Mots-clés : vieillissement, foyer de soins de longue durée, soins de longue durée, médecin, médecine, qualité

Keywords: aging, nursing home, long-term care, physician, medicine, quality

La correspondance et les demandes de tirés-à-part doivent être adressées à : / Correspondence and requests for offprints should be sent to:

Robert James, M.D.

Adjunct Professor

School of Health Policy and Management, York University

York Lanes, 359A, 4700 Keele St.

Toronto, ON M3J 1P3

<jamesra@mcmaster.ca>

Canadian Journal on Aging / La Revue canadienne du vieillissement 37 (2) : 133-144 (2018)

Copyright (C) Canadian Association on Gerontology 2018. This is an Open Access article, distributed under the terms of the Creative Commons Attribution licence (http://creativecommons.org/licenses/by/4.0/), which permits unrestricted re-use, distribution, and reproduction in any medium, provided the original work is properly cited. 


\section{Background}

The role of physicians in nursing homes is largely unexplored. Reflecting on the work of nursing home physicians, Katz and Karuza (2015, p. 728) observed that "there are few, if any, data sources that accurately portray extant practice patterns." Similarly, Schnelle (2006, p. 398) remarked that it is "surprising that we do not have better information about pivotal questions" such as the type of work physicians engage in, the outcomes of their practice, and what might constitute optimal performance.

By contrast, a robust and important literature has developed on nursing home staffing and, in particular, its relation to quality (cf. Castle, 2008; Harrington et al., 2012). This literature typically does not include physicians. Indeed, much of the literature on staffing focuses on the role of nurses and, to a lesser degree, that of care aides (cf. Castle \& Engberg, 2007; Dellefield, 2000; Hsu, Berta, Coyte, \& Laporte, 2016).

Nevertheless, there is a small but growing body of research indicating that physicians make important contributions to the quality of residents' care (cf. Katz, Karuza, Lima, \& Intrator, 2011; Lima et al., 2012; Shield et al., 2014). Further, the role of physicians is expected to gain in significance as the distinction blurs between long-term and acute care sectors (Stone, 2006), with nursing homes housing a growing proportion of subacute care patients and residents with increasingly complex care needs who are nearing the end of life.

In an effort to contribute to our understanding of the role of nursing home physicians, we present in this article the results of an exploratory qualitative study of physicians caring for residents in nursing homes across six countries. We sought to learn about physicians' roles, responsibilities, and tasks as well as to investigate the unique qualities of the practice of medicine in nursing homes and the challenges physicians routinely encounter. In particular, we sought to learn about the contributions to care that physicians make from their perspective.

\section{From "Missing in Action" to "Misunderstood"}

Much of the Anglophone research on the role of nursing home physicians has been conducted in the United States and initially focused on physicians' physical presence in the nursing home environment (Caprio, Karuza, \& Katz, 2009; Helton, Cohen, Zimmerman, \& van der Steen, 2011; Katz, Karuza, \& Kolassa, 1997). This research found great variability in physicians' presence, with only a small minority of physicians devoting a substantial portion of their working week to the care of elderly residents in nursing homes.

Physicians have been characterized as absent from the nursing home context, with an oft-cited study describing them as "missing in action" (Shield, Wetle, \& Teno, 2005, p. 1652). Families in that study reported "infrequent communication with physicians and expressed distress and at times anger about the lack of contact" (Shield et al., 2005 , p. 1653). This claim has been qualified however, by Katz and Karuza (2005, p. 1826) having argued that the role of physicians was better thought of as "misunderstood", since the data were not yet available to pass such broad judgment.

Indeed, recent research suggests that physicians can play an important role in the quality of residents' care, with their presence positively impacting a number of domains, particularly the prevention of unnecessary hospitalization (Lima et al., 2012; McGregor et al., 2014; Xing, Mukamel, \& Temkin-Greener, 2013). However, although the extent of physicians' presence remains largely unknown, a number of studies have sought to identify the factors that support or hinder visits to those nursing homes that do not have full-time physicians present (Levy, Palat, \& Kramer, 2007).

One survey-based study of physicians by Caprio et al. (2009), for instance, found that lack of nursing support and inaccurate or inaccessible information posed the greatest challenge to the number of visits made by physicians. Physicians' presence has also been explored in relation to the organization and remuneration of medical care (Katz, Scott, \& Karuza, 2012), with fee-forservice models believed to hinder visits because it is not financially worthwhile for physicians to visit a facility to see only a small number of patients. A study by Evans et al. (2012) supports this hypothesis, finding that the number of registered patients was strongly associated with nursing home visitation.

\section{Experiments in Organizing Medical Care}

Such observations have led to experiments with the organization of medical care, with some homes restricting practice to a small number of physicians directly contracted with the home, the assumption being that physicians working in such "closed" staffing models would be more committed, present, and familiar with residents and their needs. One experiment with a closed model demonstrates promise (Katz, Quail, McBryde, \& Karuza, 2011), evidencing decreases in wounds, hospitalization, hip fractures, and the use of both antipsychotics and restraints. Such results lend credence to the importance of committed physicians for quality nursing home care.

The societal and professional stigma against physicians working in nursing homes is another crucial barrier (Higashi, Tillack, Steinman, Harper, \& Johnston, 2012). Despite this perceived stigma, several studies have revealed a number of positive aspects to the job (BernKlug, Buenaver, Skirchak, \& Tunget, 2003; Frank, Seguin, 
Haber, Godwin, \& Stewart, 2006). In one qualitative study (Bern-Klug et al., 2003, p. 148), physicians reported enjoying especially the relationships involved in their work, and they described nursing home medicine as both "interesting" and "meaningful". Physicians also valued the autonomy of nursing home practice. Interestingly, these results came as a surprise to the medical students analysing the data. They did not "anticipate that physicians would report that they enjoyed the relationship aspects of their job", leading the authors to conclude that the work of nursing home medicine needs to be better understood and that "[n]ursing home success stories need to be articulated" (Bern-Klug et al., 2003, p. 150).

\section{Methods}

The purpose of this study was to learn about the role of physicians who take care of patients in nursing homes. We sought to identify patterns, similarities, and differences in the organization of their work, as well as to identify the factors that helped or hindered their efforts in an international context. Focusing on facilities with reputations for excellence, the study also sought to articulate concepts related to exemplary practice, while remaining sensitive to the challenges faced by physicians working in nursing homes.

\section{Data Production}

This exploratory, descriptive study of physicians' practice was part of a larger international, interdisciplinary study of promising practices in nursing homes across six countries: Canada, Germany, Norway, Sweden, the United Kingdom, and the United States.

Site selection in each jurisdiction was guided by keyinformant interviews conducted in 2011 with union and employer representatives, community groups, and government stakeholders. Our aim was to identify nursing homes that used practices in delivering care, in relating to residents and their families, and in intra-staff relations that we thought were worthy of study and possible emulation. Based on the list of facilities produced, a convenience sample of 21 homes was selected with the goal of including a range of ownership types and facility sizes. Ethics approval to study these sites was received from each facility, as well as from the university of the lead researcher in each jurisdiction and from York University in Canada where the project was based.

From 2012 to 2015, weeklong visits were conducted at 16 of the selected facilities by a team of researchers using the method of rapid ethnography, which incorporated documentary analysis, on-site observation, and interviews to produce a holistic understanding within a short time frame (Baines \& Cunningham, 2011).
In addition to longer visits, a number of one-day "flash" visits were conducted at the remaining five selected facilities. A convenience sample of 15 physicians was interviewed for a total of 13 sites (see Table 1). All except two of these sites were urban nursing homes. The homes ranged from midsize ( $\approx 60$ beds) to large ( $\approx 200$ beds) and included nonprofit, municipal, and for-profit homes. In one large home, three physicians were interviewed.

Prior to each interview, the project was described both orally and in writing, and physicians signed an informed-consent form. Interviews were conducted in English by a project researcher trained in ethnographic methods. Interviews were conducted in collaboration with a local researcher to assist, if necessary, with language in non-English-speaking countries. Interviewers participated in the week-long site visit to ensure familiarity with the facility and conducted additional interviews with residents, nursing, management, and care aides, although those results are not included here.

Interviews with physicians were guided by a semistructured protocol, developed by RJ, a former nursing home medical director, in collaboration with the other authors of this article. The interviews were designed to address a range of topics, including training, employment, responsibilities, work organization, tasks, job satisfaction, accountability and quality of care. Three pilot interviews were conducted in which the interview questions were refined. One pilot was conducted with a medical director of a Canadian nursing home, and two were with physicians who had previously

Table 1: Study facilities for physicians caring for elderly residents - locations and codes

\begin{tabular}{|c|c|c|}
\hline Location & Code & Physicians (\#) \\
\hline \multicolumn{3}{|l|}{ Canada } \\
\hline British Columbia & $\mathrm{CA} / \mathrm{BC}$ & 3 (including 1 pilot) \\
\hline Manitoba & $\mathrm{CA} / \mathrm{MB}$ & 1 \\
\hline Ontario & $\mathrm{CA} / \mathrm{ON}$ & 2 \\
\hline Nova Scotia & CA/NS & 1 \\
\hline \multicolumn{3}{|l|}{ Germany } \\
\hline North Rhine-Westphalia & GM/NRW & 1 \\
\hline \multicolumn{3}{|l|}{ Norway } \\
\hline Pilot & NW/Pilot & 1 \\
\hline Oslo & NW/Oslo & 1 \\
\hline Bergen & NW/Bergen & 3 \\
\hline \multicolumn{3}{|l|}{ Sweden } \\
\hline Stockholm & SW/Stockholm & 2 \\
\hline \multicolumn{3}{|l|}{ United Kingdom } \\
\hline Bristol & UK/Bristol & 1 \\
\hline \multicolumn{3}{|l|}{ United States } \\
\hline California & US/CA/Pilot & 1 \\
\hline Texas & US/TX & 1 \\
\hline Total & & 18 \\
\hline
\end{tabular}


worked in nursing homes for more than a decade but presently occupied an academic (Norway) and an executive (United States) position respectively. These interviews were included in the analysis.

The interview protocol was not rigidly adhered to but used in a dialogical manner in order to allow researchers to explore topics raised by interviewees. The result was rich data on the experience, responsibilities, and concerns of physicians working in nursing homes in the six countries. In total, we conducted 18 interviews, each lasting approximately one hour. All were audio-recorded, then professionally transcribed verbatim.

\section{Data Analysis}

Data analysis was iterative and involved several steps (Patton, 1990). Data were analysed by RJ working with a research assistant and independently by $\mathrm{AB}$. In this process, transcripts were coded with emergent codes as well as analytic codes reflecting the projects' sensitizing concepts (e.g., work organization, promising practices, accountability, quality of care).

Using the coded transcripts produced by the two analyses, summaries were developed by $A B$ for each physician that described their roles, responsibilities, and tasks, as well as promising practices and/or barriers to quality care, with differences between the independent analyses providing important insights.

Preliminary theme generation was performed manually by $A B$ through a cross analysis of the physician summaries and repeated readings of the transcripts as well as note-taking to capture analytic insights and illustrative quotes (Birks, Chapman, \& Francis, 2008). All authors collectively discussed the emerging themes during monthly data analysis meetings, during which missing issues were identified as were themes with insufficient data to support them. The interview transcripts were then re-read by $A B$ to further develop the analysis as well as identify negative cases, resulting in the thematic analysis presented below.

We ensured the credibility of the results through partnered interviewing, independent and collective interpretation of data, the use of negative case analysis, and the use of an audit trail. Nevertheless, we caution that the sample is small. This limits the possibilities for generalization and cross-jurisdictional comparisons. Still, at various points, those we interviewed highlighted instances where their practice was atypical and, therefore, worth noting or where jurisdictionallevel policies and practices helped or hindered their work. As this was an exploratory study, we note that these observations may indicate areas meriting further research.

\section{Sample Characteristics}

Eighteen physicians (nine men and nine women) were interviewed. Seven physicians worked in Canada, five in Norway, two in each of Sweden and the United States, and one in each of Germany and the United Kingdom. In the following discussion, we refer to physicians with alphanumeric codes to ensure anonymity while representing jurisdiction (see Table 1). We used a twoletter code for the country, the city name or a two-letter code for province/state, and a number to refer to the particular physician if there was more than one interviewed in that jurisdiction (e.g., CA/NS2). The word "pilot" in a code indicates that the response came during one of our three pilot interviews.

Only three of the 18 physicians interviewed were geriatricians, with the rest being general practitioners/ family physicians. Four had received some geriatric training in medical school, six completed additional courses in geriatrics or palliative care since graduating, and the rest reported no specialty geriatrics or palliative care training. Most reported "falling into geriatrics" and "learning on the fly".

The means of contracting, remunerating, and organizing medical care was diverse. In Canada and the United States, physicians were typically paid through a fee-forservice scheme, although concerns were expressed that this model "intends the wrong things" (CA/BC3). In one case, a U.S. physician reported successfully negotiating a salaried position, although she acknowledged this was "unusual" (US/CA/Pilot).

It was also typical for physicians to combine their nursing home practice with other medical work - for instance, family or emergency medicine. Seven physicians were employed as medical directors, several of whom worked as directors in more than one facility. One medical director (US/CA/Pilot) worked as a director of seven facilities at one time. Medical director positions did not exist in Norway, Sweden, Germany, or the United Kingdom.

Three of the Canadian homes had moved to a closed model of organizing medical care with physicians contracted directly by the home and responsible for a minimum number of residents (usually no less than 20). Thus, one home we visited in British Columbia had four physicians responsible for the care of approximately 125 residents, and, similarly, a home we visited in Nova Scotia had dedicated "per-floor physicians", part of a model of care intended to enhance physician engagement that was being rolled out across the province. In Manitoba, the medical director was responsible for all residents at the home (approximately 80). However, this organizational style was an unintended consequence resulting from the departure of a colleague 
who was "overwhelmed by the family, social issues that occur", issues exacerbated by the "dumping" of "tough to manage residents" in the home. No replacement was being sought, because both the medical director and administration felt the current arrangement worked: "I've really connected well with the families and residents" (CA/MB).

In the United Kingdom, the physician we interviewed worked as a full-time general practitioner, employed at a clinic near to the home; 40 of the home's residents were his patients through this clinic. Similarly, the German physician worked at a nearby clinic and was responsible for 60 of the home's residents. In one Swedish home, the physician was directly contracted by the home, worked half-time, and was responsible for nearly 100 residents. At another Swedish home, the physician was responsible for all (approximately 100) residents but saw them as patients of a municipal clinic, where he was employed full-time and paid a salary. He also worked in two other nursing homes. In Norway, two physicians in the largest home were "house physicians", contracted by the home, salaried, and working full-time, although we were told this full-time house model was atypical.

\section{Results}

In presenting the results of our study, we first discuss contributions to quality followed by the importance of relationships to medical care.

\section{Contributions to Quality}

Physicians reported playing important roles in a number of areas of relevance to the quality of resident care, working to reduce residents' medications and hospitalization, clarifying the goals of care with staff and family, and in contributing to staff education, particularly around end-of-life care.

\section{Reducing Polypharmacy}

All of the physicians we interviewed expressed a commitment to the assessment and reduction, where appropriate, of residents' medication. Poly-pharmacy was a concern; as a U.S. physician expressed it, "[Residents have] seen many, many doctors, and every doctor along the way has added a medication. Every doctor is afraid of taking off the medication because somebody else added it. Unfortunately, they don't want to step on anybody's toes" (US/TX).

Physicians routinely reviewed residents' medications. Medication reviews required a holistic analysis, which one Norwegian physician suggested was a good approach to medical treatment:

For me as a new doctor it was a very good start into medication and looking at the patient as a whole in regards to the chronic diseases he or she has, and the interactions, and which medication does the patient need: Is this something that prolongs or enhances their life? (NW/Bergen2)

A number of conditions were observed to support physicians' efforts to appropriately reduce medication. Having enough time with residents was essential. In Norway and Sweden, where there were house physicians, this was expressed as having a "good physician to resident ratio". In the United Kingdom, the physician was supported by a primary care liaison service that allocated community psychiatric nurses to the home:

\begin{abstract}
So the immediate reaction is not always just to prescribe. It's to perhaps get somebody with a bit more time than me to sit down and do an assessment and then they may say "yeah, this person is low, we need to treat them with antidepressant medicine and here's the plan" and then we've got a plan. I think that's probably a more patient-centered approach than, you know, me coming in and I'm just seeing ten patients in 50 minutes. It's very easy to prescribe. We work quite closely with them. (UK/Bristol)
\end{abstract}

Access to specialists, such as geriatric psychiatrists or neurologists, was particularly important "when the usual stuff isn't working" (CA/NS). One physician in Norway, for instance, had access to a facility specializing in geriatric psychiatry for consultation and where the resident could be sent for evaluation: "When they come back ... the medication is working better" (NW/Bergen2).

Several physicians experienced pressure to medicate from nurses. "I don't think that we are actually given the right to be a demented person," observed one physician. He went on to suggest that an aspect of medication reduction involved deciphering who the medication was really helping. "Who is being bothered? Is it the patient or the caregivers?" (US/TX). Several physicians understood this pressure as reflecting insufficient staffing. As a Canadian medical director for three homes remarked,

It takes a lot of time and patience to deal with these folks. My frustration is that [the staff] want to have medication. They don't want to take the time to figure out what is needed... Because they don't have the staff. It is the same everywhere. (CA/NS)

Encouraging staff to adopt behavioural approaches to agitation and verifying that this had been attempted was presented as an important part of physicians' responsibility. Sometimes, however, a stronger approach was necessary:

I challenge the nurses. I don't get bullied by the nurses. I mean there's homes where the nurses tell you what to do and that they expect it. That drives 
antipsychotic use. Sorry. But nurses do drive antipsychotic use I think in the homes, not the physicians. (CA/MB)

\section{Reducing Hospitalizations}

Another area where physicians made important contributions to resident care was in the reduction of hospitalizations, which physicians felt could be "stressful" for residents and could result in residents' undergoing unwanted and/or unnecessary interventions as well as returning to the home with bedsores.

Access to physicians was perceived as critical here. Indeed, the closed model of physician employment was explained as a method of increasing physician presence and thereby reducing hospitalizations. For instance, the "dedicated per-floor physician with 24-hour on-call physician coverage" was a key pillar of a provincial "Care-by-Design" program being rolled out across Nova Scotia and implemented at the facility we visited. Preliminary data indicate the program has brought emergency transfers down by 40 per cent to 65 per cent (Glauser, Taylor, \& Bournes, 2015).

Gaps in on-call coverage were noted as contributing to unnecessary hospitalization, and this was an area of concern in many of the homes we visited. One physician described off-hours as a "dog's breakfast" (CA/BC3). Yet, there was surprising variation in the organization of the on-call systems as well as physicians' access to patients' records when away from the facility. Efforts to implement new communication protocols were ongoing in several jurisdictions (e.g., Sweden, Norway, Canada), although there was a noted absence of any standard practice that alleviated the problem.

Access to diagnostic and technical capacity was observed to reduce the need for hospital transfers: for instance, having access to scanners to measure the volume of urine in the bladder, mobile X-ray devices, or access to outreach nurses who could administer IVs. As the German physician admitted: "You only have a few possibilities of diagnostics. Only your ears and your hands and something like that and probably a lab test ... If there is anything I can't do here I have to send them to hospital" (GM/NRW).

Working with "unknowns" was a unique feature of nursing home medicine because residents were often too frail to undergo transportation for diagnostic procedures or to see specialists. An important skill was the ability to work in the face of this uncertainty:

You're having to make a decision about what to do in the context of not knowing everything ... So that's something that's big in long-term care and talking about the communication with families and the staff around that when it's not really clear exactly what the right answer is. (CA/ON1)
This physician went on to add that while she enjoyed this aspect of the work, not everyone did. She noted her younger colleague was unprepared for this level of uncertainty and ultimately quit.

\section{Clarifying Goals of Care}

Uncertainty exists with respect to not knowing what the problem is and also with respect to whether or not trying to correct the problem is likely to benefit the resident. Thus, physicians reported that an important part of their job was to clarify the goals of residents' care, which included addressing end-of-life care. This responsibility was particularly heightened in the context of changing demographics of resident populations observed at most sites, with residents entering older and sicker. In one Canadian home, 47 per cent of the residents did not live longer than three months after entry into the home. "We feel like an acute medical unit," remarked the physician there $(\mathrm{CA} / \mathrm{BC} 2)$.

Addressing end-of-life care involved preparing families and managing expectations. As one physician explained:

I often try and give a sense of "Your loved one is gradually declining. We're going to be looking at these issues." You start to prepare them. These are things we might see in this scenario. The way care direction stands now, we would be obligated to do this: "Is this something you still want?" (CA/ON1)

The outcome of these conversations was documented to serve as a reference. However, when the resident was sick or actively dying, this physician noted that "there's often more visits and more phone calls just with updates and making sure that we're doing the right thing."

A number of physicians insisted it was essential to address end-of life care early, ideally during the admission conference, although one Canadian physician felt such a venue was not intimate enough. She would strive to create another opportunity to converse with family following the conference, although she acknowledged not all physicians did this. The annual review also presented an opportunity for physicians to clarify goals of care. However, conversations could be triggered by a noted change in a resident's health. In these cases, the nursing staff usually detected a need to address end-oflife care, a typical trigger being "the person is eating very little or maybe it's observed that he cannot really eat any more" (SW/Stockholm1). The nurse would then prompt the responsible physician to speak with the family.

Clarity and consensus about the goals of care were essential to avoiding unnecessary medicalization, as one Canadian physician explained:

If you get that conversation happening correctly, then everybody starts to get more on the same page. 
That it's less and less about fixing things medically because we're past the "being able to fix". We can support. We can comfort. (CA/BC3)

Similarly, observations were routinely offered on the importance of these conversations for the prevention of hospitalization: "End-of-life care is a very good place to [reduce hospitalization] and to do more realistic care, care that makes people comfortable and not sending them back and forth" (CA/ON2).

However, several physicians conceded that goals-ofcare conversations were not happening as early or routinely as they should, and one Norwegian physician admitted that the frankness around dying was recent. "Five years ago it would be difficult. We didn't talk so openly about it. We were not so honest. We were more nervous in how to talk with the patients and with the family and with the nurses also" (NW/Oslo). He went on to add that these conversations were not easy; he had mixed feelings about them. "Sometimes I don't want so much pressure. I don't want the big questions. Sometimes I want it. It's a bit difficult."

\section{Education}

Another pattern we discerned was physicians' commitment to education. One physician felt his institutional accountability included ensuring that "staff have the best possible knowledge and education in the area they were working. So, for instance, in my case I used some of my time teaching the nurses and the other personnel to give the whole institution better total competence" (NW/Pilot).

Commitment to education was particularly evident around end-of-life care. One physician, for example, was undertaking a health literacy project to prepare family in "a bit more of a systematic way rather than the very time-intensive one-on-one" (CA/BC2). Four physicians reported recently completing palliative care training and were actively involved in sharing their knowledge with both staff and families. One physician was involved in developing palliative care courses for nursing home staff at a national level. Another physician had received specialized training in frailty and dementia trajectories, which she was teaching staff - predominantly nurses - during care conferences, although hopefully, she said, to care aides in the future. This training helped place the resident within a trajectory that included dying, and which enabled staff to engage questions about the goals of care. "Since I started modelling these questions and modelling these things at the care conferences, now all the staff know ..." (CA/BC2).

Writing extended medical notes was another way physicians tried to educate staff and improve care. As one Canadian physician explained:
My notes are a little longer I think in some cases ... you'll see a long piece about why I'm doing something, what the differential [diagnosis] is and the reasons I've chosen what I've chosen ... So every nurse that comes on shift can actually see that and go and review how I'm addressing it and, you know, maybe support that. And they talk to the families. But also they understand why I'm not just throwing out this medication or why I'm taking a different approach or what some of my concerns are. Sometimes the nurses respond by writing their own note afterwards which is good. That's the way we communicate. (CA/MB)

He cautioned that this was an atypical practice:

[As a medical director] I've had to audit other charts, and docs write one line and they just write their diagnosis. Sometimes they don't even write the diagnosis. They just write the treatment, and so everyone is guessing that they're treating for this reason. $(\mathrm{CA} / \mathrm{MB})$

\section{Relationships}

Whether or not physicians were employed directly by the home or saw residents as private patients, physicians reported that their work involved them in a network of relationships that were fundamental for delivering medical care. These relationships were essential for both the quality of care and for their satisfaction on the job. The most immediate relationships in the home were with residents and staff; less frequently, physicians related to families and administration.

\section{Residents}

Becoming familiarized with residents was noted by several physicians to be an enjoyable and rewarding part of the job. However, it took time and energy. It required, as several physicians noted, making an effort to see residents when they were well.
When I come here I feel that it's just as important to see people when they're well as when they're sick ... I actually walk around and I visit with resi- dents ... I take the time to learn who they are, know something about them. I think that for me gives me a more rich and rewarding practice than just coming here and putting out fires. (CA/MB)

Familiarity with residents was not only personally satisfying but medically relevant, particularly in the context of dementia. Familiarity was reported to be essential for enabling decision-making that supported what mattered to residents, helping physicians make those "holistic, patient-centred, best-interest decisions". As the U.K. physician went on to explain:

It's more difficult if you don't know the patient to make those decisions where: Actually is this in the person's best interest to actually admit them 
to hospital ...? What are we actually trying to treat them back to? Are they trying their best to die and is medical intervention getting in the way of that? What's the quality of life like? All those questions. (UK/Bristol)

Providing treatment that was in the interests of residents was an important benchmark for accountability according to several physicians; this focus was particularly germane in light of the number of oversight bodies regulating residential care. "As long as I'm doing justice by the patient I'm fine. I can justify it to all the other persons ... you know, as long as the patient is cared for I think all bets are off on everybody else" (US/TX).

\section{Staff}

Although physicians were responsible for medical care, they depended on nursing home staff to deliver the care. Physicians reported having most contact with registered nurses and, to a lesser degree, licensed practical nurses (or their equivalents) and aides. Several physicians explicitly recognized the importance of RNs to patient care, noting they were "the hub and then everyone else is the spokes around the wheel" (CA/MB). However, one physician asserted the importance of aides and expressed concern that they were often excluded (e.g., from care conferences). He felt it was part of his role to support them. "It's important as a doctor to encourage a residential care aide ... They [are] the stalwarts of [care] work" (CA/BC/Pilot). Similarly, another physician admitted his concern with the treatment of aides and was particularly troubled by their low status and low wages. "It's difficult to talk about dignity when the staff doesn't have dignity" (NW/Bergen3).

Physicians noted that being able to work with staff as a team was essential for quality care. Not least was that this required respect, trust, and good communication. Most physicians said they respected the nursing staff and admitted that they were better than at the other homes where the physicians worked (e.g., more organized, better communicators, more competent). It was particularly important for physicians to trust nurses to voice concerns, and they preferred this communication to take place when the background work regarding the problem was completed. "Not just coming to me and saying 'something's wrong' but if they have prepared, it's much easier for me. It takes less time. It's more secure ... I can feel confident with this person so I don't have to double-check. I can trust them" (SW/Stockholm1).

Communication between physicians and nurses was particularly important and, as noted, was a challenge when physicians were not on site. However, good communication involved more than sharing information about residents: it required listening and adapting to multiple perspectives. Working in a nursing home "is a different realm of medicine. You need a lot of patience and to be willing to work in a team, where a nurse has an opinion, a [personal care worker] has an opinion, a director has an opinion" (CA/NS).

Good teamwork was important but could be threatened by hierarchical relationships. "It requires physicians not to create a hierarchy ... and work collaboratively" (CA/MB). Several physicians raised concerns about colleagues who had a "paternalistic" approach to nurses. Others noted using their power strategically for instance, by intervening to mitigate the abuse of staff by residents or family. However, points of tension were mentioned around the pressure to prescribe, to which one physician responded by keeping relations "a bit strict" with nurses. "They want me just to sign something. They don't actually want me to do my assessment" (NW/Bergen1).

\section{Families}

Relating to families was another unique aspect of the nursing home environment and could push the boundaries of what counted as medical work. One medical director reflected that, prior to her geriatric training, she would have said "family problems were not my problem" (CA/NS). Now she compares geriatrics to pediatrics where "you have to work with the family". As with other staff, families required physicians to attend to and integrate a diversity of perspectives, broadening their lens beyond the conventional biomedical domain.

I think that's the part of the visual, that you have this wide perspective. You have to adjust how you think, and how you work, and how you plan. It depends. There are sons and daughters, and it depends on the whole situation. I think that's a kind of a challenge as well in the work. (SW/Stockholm2)

Although some physicians derived satisfaction from working with families, families were more commonly represented as challenging, requiring physicians to adopt a "social worker hat" approach. "Most of the stress comes from family issues which is typical I think in most care homes" (CA/MB). However, several physicians noted that this stress was exacerbated by, or a result of, not having enough time to spend with families: "that's the problem" (SW/Stockholm2).

\section{Physicians}

Relationships with other physicians contributed to the vibrancy and quality of the work. Discussing cases with colleagues was observed to be particularly important given the uncertainty of the practice, and several physicians reported brainstorming cases with their colleagues. "The doctors here - we discuss a lot 
among each other so very often we collectively discuss a patient and then determine the best actions forward" (NW/Bergen2).

One Canadian physician (CA/BC3) received specialty training in palliative care through a physicians' network, which she went on to disseminate throughout her facility. The training also helped alleviate pressure to hospitalize. At the time of interview, the network was collecting data on transfers to acute care with the goal of using this information as an indicator of the quality of communication about goals of care. Another physician (SW/Stockholm2) reported working parttime for a government policy body. She felt that this involvement allowed her to integrate the latest guidelines into her work while using her experience to shape policy.

Several Canadian medical directors participated in regular gatherings of regional medical directors to "address problems in terms of relationships, delivery of care and teamwork", according to a Nova Scotia physician (CA/NS). These gatherings afforded an opportunity to discuss difficult cases and also contributed to systemic improvement, allowing medical directors to collectively identify and resolve problems. For instance, one group was surveying nursing home physicians to see how their job could be made "more efficient and pleasant" (CA/NS). Another group had identified gaps in care and developed an innovative on-call system to address this. Their meetings also afforded an opportunity to influence policy, as representatives from the regional health authority would attend.

These meetings added vibrancy to the work:

\begin{abstract}
It definitely helps having those monthly meetings the nucleus which can be a clinical topic - because it keeps the interest up, keeps our interest in residential care. Very often I think we, me included, are guilty of thinking that residential care is a fairly static discipline that doesn't change very much. That's not the case. There's always things that we can improve on. There's always clinical things that we can influence. (CA/BC/Pilot)
\end{abstract}

Indeed, one of the limitations of the full-time housephysician model, according to one Swedish physician, was that "you work quite alone" (SW/Stockholm2). In this context, she reported having to plan meetings with other physicians because they didn't happen organically. She also noted that this isolation might eventually result in her leaving the field. "I don't think I would continue with this work for 20 years. No. Because ... you need that inter-collegial stimulation."

\section{Administration}

Relationships with administration were mainly reported by medical directors. However, there was considerable variability in their engagement with administrators. One medical director observed that he was not directly involved with administration, although he did serve in an advisory capacity and developed medical protocols for the home (e.g., criteria for new admissions). Another medical director expressed the desire to be more active but found the bureaucracy inhibiting.

I tend to get involved with things as they come up, and I kind of proactively want to ... you know, I go to conferences and okay, we have to change this and then there seems to be red tape and then I lose my interest ... I find it very frustrating. (CA/ON2)

There was also variability in the openness of management to medical directors' participation:

There's some places where you're sort of kept at an arm's length and "You can be our medical director but keep your ideas to yourself" and then there's others that really enjoy working together like in a team and in a collaborative way. (CA/NS)

Indeed, she went on to note that she was experiencing resistance from the current administration, which she characterized as a lack of openness to change, a problem which was being addressed at the time of interview.

One medical director who had worked in seven homes believed that the openness of these relationships was related to ownership status:
I really felt that I wanted to be part of these nursing homes, to try to make a difference, to be not just a distant, passthrough medical director ... But I found it so much more challenging to do that in a corporate for-profit setting. (US/CA/Pilot)

She went on to suggest this was because the large corporations she worked with tended to set "their policies from on high". They were therefore insensitive to local patient mixes, and their primary concern was costs, not care.

\section{Discussion}

As part of a larger project investigating promising practices in nursing homes, this interview-based exploratory study sought to describe physicians' roles and responsibilities from their perspective. Physicians reported playing an important role in a number of areas of relevance to the quality of residents' care, working towards the reduction of polypharmacy and hospitalization, clarifying the goals of care, and contributing to the education of staff and families, particularly about end-of-life care.

One point of resistance to greater physician presence in nursing homes has been the concern that their involvement will lead to medicalization, with a focus on pathology, resulting in increased testing and treatment (Stone, 2006, pp. 460-461). There is some justification 
for these worries. As the physicians we interviewed observed, without adequate time to become familiar with residents, share knowledge, and co-ordinate care with staff, the default was to prescribe or hospitalize, sometimes as a result of pressure from other staff.

Nevertheless, our results suggest that the opposite of medicalization occurs when physicians are actively engaged in a holistic, person-centred, relational practice and, specifically, one that recognized the context of dying. The physicians we interviewed were committed to the reduction of unnecessary medication and hospitalization. Our findings point to a number of factors that would further support their efforts, including (1) systematic medication reviews that included medication reduction as a goal; (2) access to diagnostic technology; (3) access to patient information when not in the home; (4) access to specialists; as well as (5) palliative care training and (6) good on-call coverage. Some of these factors, particularly medication reviews and palliative care training, are starting to receive attention from researchers (Bain et al., 2008; Chiua, Berob, Hessol, Lexchin, \& Harrington, 2015; Phillips, Davidson, \& Willcock, 2009), yet there is a noted lack of promising practices around the design of on-call systems and electronic information sharing.

Although this study and others have found social relations critical to nursing home care (Banerjee \& Armstrong, 2015; Colón-Emeric et al., 2006; Robinson et al., 2012), the relational dimension of nursing home medicine has received scant attention. This neglect is particularly troubling given that concerns about medicalization are typically framed as a tension between medical and social models of care (Stone, 2006). However, as most physicians we interviewed indicated, social relations were central to their work. For example, developing familiarity with residents and their families was essential to providing medical care that was sensitive to residents' wishes. Teamwork was also a key feature of nursing home medicine. Teamwork, according to those we interviewed, required integrating multiple perspectives and ensuring good communication and co-ordination with staff as well as families. Moreover, pressure for drug prescribing was sometimes experienced from nurses. It was suggested that this might be a result of heavy workloads in which behavioural strategies were impractical, an issue having more to do with staffing and funding than the presence of physicians. Accordingly, the findings from this study challenge the oft-drawn boundaries between the medical and the social, indicating that good medical practice in nursing homes was also good social practice.

Our exploratory study suggests that one promising approach to quality improvement in nursing homes would involve better understanding the relational dimensions of medical practice in this unique context as well as how these relations may be supported. As we have noted, ensuring continuity of communication when physicians are not physically present is an area requiring further research. Supporting such continuity would ensure that nursing home staff are able to collaborate with physicians they know and trust, and who are familiar with their residents. Equally important, however, is addressing the structural conditions that prevent physicians from being present in the first place. The limitations of fee-for-service schemes in this regard were noted by several of those we interviewed, yet there is little research exploring alternatives within nursing homes (Katz et al., 2012). What's more, the time it takes for conversations that are required to care well are not adequately compensated within this scheme, as several doctors noted. This raises questions around how physicians might be remunerated such that they have the time to engage in the dialogues that are essential to developing familiarity, determining the goals of care, and preparing families for the passing of their loved ones.

Our study also found that relationships outside the home were important. Physicians' participation in medical networks played an important role in integrating new knowledge, skills, and promising practices within the home. This aspect of physicians' work has not been well represented in the research literature and might be explored as a contributor to physician engagement and leadership. Participation in physicians' networks may also help mitigate the isolation that some doctors reported. This isolation was experienced by physicians contracted with homes, revealing a potential downside of the closed model of employment. Although these closed approaches contribute to physician presence and familiarity with residents (Katz, Quail, et al., 2011), they may not provide sufficient inter-collegial stimulation. This is clearly relevant to job satisfaction and possibly physician retention, but it may also have clinical implications. Given that interviewees noted that high levels of uncertainty were a unique feature of nursing home medicine, opportunities to consult with colleagues may be particularly relevant to good medical care in this context. How might these relations be fostered? At the same time, given that many of the physicians we interviewed held positions across a number of homes, they occupy a unique insider/outsider position that could afford opportunities for further knowledge sharing and accountability. How to develop these linkages as opportunities is another area meriting further exploration.

Finally, as noted, several limitations of our study are worth recalling. Among these is the small sample of physicians in each country, which prohibits descriptive claims about the organization and delivery of medical care at a national level. In addition, we did not explore whether the physicians felt that their experiences and 
perspectives were shared by their colleagues in their respective countries. Nor can we claim the facilities visited or physicians interviewed were typical. Indeed, we know they were not. These sites were chosen because they were exemplary, and the aim of this study was not to describe typical practice but to identify promising practices in nursing homes. Another limitation of this study is that it focused on the physicians' perspective. Although the larger study did include other staff, residents, and family members, we generally did not inquire as to how they perceived medical care nor how they related to physicians. Despite this limitation, the voices of physicians are all too often absent in studies of nursing home care, and we have gone some way to addressing this gap - hopefully spurring greater attention to the role of physicians on the nursing home care team and to the various ways in which medical care may be organized and delivered.

\section{References}

Bain, K., Holmes, H., Beers, M., Maio, V., Handler, S., \& Pauker, S. (2008). Discontinuing medications. JAGS, 56(10), 1946-1952.

Baines, D., \& Cunningham, I. (2011). Using comparative perspective rapid ethnography in international case studies. Qualitative Social Work, 12(1), 73-88.

Banerjee, A., \& Armstrong, P. (2015). Centering care: Explaining regulatory tensions in residential care for older persons. Studies in Political Economy, 95, 7-28.

Bern-Klug, M., Buenaver, M., Skirchak, D., \& Tunget, C. (2003). "I get to spend time with my patients": Nursing home physicians discuss their role. JAMDA, 4(3), 145-151.

Birks, M., Chapman, Y., \& Francis, K. (2008). Memoing in qualitative research: Probing data and processes. Journal of Research in Nursing, 13(1), 68-75.

Caprio, T., Karuza, J., \& Katz, P. (2009). Profile of physicians in the nursing home. JAMDA, 10(2), 93-97.

Castle, N. G. (2008). Nursing home caregiver staffing levels and quality of care. Journal of Applied Gerontology, 27(4), 375-405.

Castle, N. G., \& Engberg, J. (2007). The influence of staffing characteristics on quality of care in nursing homes. HSR: Health Services Research, 45(2), 1822-1847.

Chiua, Y., Berob, L., Hessol, N. A., Lexchin, J., \& Harrington, C. (2015). A literature review of clinical outcomes associated with antipsychotic medication use in North American nursing home residents. Health Policy, 119, 802-813.

Colón-Emeric, C. S., Ammarell, N., Bailey, D., Corazzini, K., Lekan-Rutledge, D., Piven, M. L., ... Anderson, R. A. (2006). Patterns of medical and nursing staff communication in nursing homes: Implications and insights from complexity science. Qualitative Health Research, 16(2), 173-188.
Dellefield, M. E. (2000). The relationship between nurse staffing in nursing homes and quality indicators: A literature review. Journal of Gerontological Nursing, 26(6), 14-28.

Evans, G., Grimley Evans, J., \& Lasserson, D. S. (2012). Questionnaire study of the association between patient numbers and regular visiting by general practitioners in care homes. Age E Ageing, 41(2), 269-272.

Frank, C., Seguin, R., Haber, S., Godwin, M., \& Stewart, G. (2006). Medical directors of long-term care facilities. Canadian Family Physician, 52, 752-753.

Glauser, W., Taylor, M., \& Bournes, D. (2015). Why do so many nursing home residents end up in emergency departments? Healthy Debate. Retrieved from http:// healthydebate.ca/2015/2012/topic/nursing-homeslong-term-care-emergency-department-avoidance

Harrington, C., Choiniere, J., Goldmann, M., Jacobsen, F., Lloyd, L., McGregor, M., ... Szebehely, M. (2012). Nursing home staffing standards and staffing levels in six countries. Journal of Nursing Scholarship, 44(1), 88-98.

Helton, M. R., Cohen, L. W., Zimmerman, S., \& van der Steen, J. T. (2011). The importance of physician presence in nursing homes for residents with dementia and pneumonia. Journal of the American Medical Directors Association, 12(1), 68-73.

Higashi, R. T., Tillack, A. A., Steinman, M., Harper, M., \& Johnston, C. B. (2012). Elder care as "frustrating" and "boring": Understanding the persistence of negative attitudes toward older patients among physicians-intraining. Journal of Aging Studies, 26(4), 476-483.

Hsu, A. T., Berta, W., Coyte, P. C., \& Laporte, A. (2016). Staffing in Ontario's long-term care homes: Differences by profit status and chain ownership. Canadian Journal on Aging, 35(2), 175-189.

Katz, P., \& Karuza, J. (2005). Physician practice in the nursing home: Missing in action or misunderstood. JAGS, 53(10), 1826-1828. doi:10.1111/j.1532-5415.2005.53509.x

Katz, P., \& Karuza, J. (2015). Physician practice in post-acute and long-term care. JAMDA, 16, 728-730.

Katz, P., Karuza, J., \& Kolassa, J. (1997). Medical practice with nursing home residents. JAGS, 45, 911-917.

Katz, P., Karuza, J., Lima, J., \& Intrator, O. (2011). Nursing home medical staff organization: Correlates with quality indicators. JAMDA, 12(9), 655-659.

Katz, P., Quail, P., McBryde, M., \& Karuza, J. (2011). Physician practice in the nursing home: Exploring new models. CGS Journal of CME, 1(1), 23-27.

Katz, P., Scott, K., \& Karuza, J. (2012). Has the time come for salaried nursing home physicians? JAMDA, 13, 673-674.

Levy, C., Palat, S.-I. T., \& Kramer, A. (2007). Physician practice patterns in nursing homes. JAMDA, 8(9), 558-567. 
Lima, J. C., Intrator, O., Karuza, J., Wetle, T., Mor, V., \& Katz, P. (2012). Nursing home medical staff organization and 30-day rehospitalizations. JAMDA, 13(6), 552-557.

McGregor, M. J., Abu-Laban, R. B., Ronald, L. A., McGrail, K. M., Andrusiek, D., Baumbusch, J., ... Kuramoto, L. (2014). Nursing home characteristics associated with resident transfers to emergency departments. Canadian Journal on Aging, 33(1), 38-48.

Patton, M. (1990). Qualitative evaluation and research methods. Beverly Hills, CA: SAGE.

Phillips, J., Davidson, P. M., \& Willcock, S. (2009). An insight into the delivery of a palliative approach in residential aged care. Journal of Applied Gerontology, 28(3), 395-405.

Robinson, C. A., Bottorff, J. L., Lilly, M. B., Reid, C., Abel, S., Lo, M., \& Cummings, G. G. (2012). Stakeholder perspectives on transitions of nursing home residents to hospital emergency departments and back in two Canadian provinces. Journal of Aging Studies, 26(4), 419-427.

Schnelle, J. (2006). Commentary on "The nursing home physician workforce". JAMDA, 7, 397-398.

Shield, R., Rosenthal, M., Wetle, T., Tyler, D., Clark, M., \& Intrator, O. (2014). Medical staff involvement in nursing homes. Journal of Applied Gerontology, 33(1), 75-96.

Shield, R., Wetle, T., \& Teno, J. (2005). Physicians "Missing in Action". JAGS, 53(10), 1651-1657.

Stone, R. (2006). Physician involvement in long-term care: Bridging the medical and social models. JAMDA, 7(7), 460-466.

Xing, J., Mukamel, D., \& Temkin-Greener, H. (2013). Hospitalizations of nursing home residents in the last year of life. JAGS, 61(11), 1900-1908. 